\title{
GEOLOGICAL SCIENCES
}

\author{
MONITORING OF NATURAL METHANE EMISSIONS \\ IN THE BLACK SEA BY REMOTE SENSING OF THE EARTH \\ ACCORDING TO THE MODIS SATELLITE (AQUA / TERRA)
}

\section{Tetiana Melnichenko ${ }^{1}$}

DOI: https://doi.org/10.30525/978-9934-26-050-6-11

This publication presents a continuation of a series of studies related to the study of the process of natural methane emissions in the Black Sea using the method of remote sensing of the Earth on the example of the north-western shelf in the Paleo-delta of the Dnieper. According to preliminary geologicalgeophysical, acoustic and geochemical data, natural gas yields with a chemical composition of up to $95-99 \%$ methane are periodically activated in this area.

The phenomenon of activation of methane seeps is widespread worldwide and attracts the attention of scientists and researchers from around the world. First, emission activity increases during periods of seismic activity in the region, which allows monitoring of the frequency and volume of gas emissions. Secondly, it is possible to study this process in detail according to space images, using a certain methodological algorithm.

This study presents a method of studying methane seeps in the marine environment according to the interpretation of MODIS space images (Aqua / Terra) with processing in specialized programs (SNAP, Q-Gis, etc.). To use the proposed method requires a preliminary geological study of the study area and determine the period of survey, including images with the most informative, associated with seismic activity of the region and the atmospheric phenomenon - cloudiness or lack thereof.

Introduction. Natural methane emissions in the aquatic environment are associated with gas hydrate deposits, which are distributed on the planet mainly in the shelf zone of the Pacific, Atlantic, Indian and Antarctic Oceans; near the coasts of North and South America, India, Japan, Norway and other countries.

In the Black Sea region, active gas manifestations were recorded almost on the entire shelf: Ukraine, Romania, Bulgaria, Turkey, Georgia and Russia. In Ukraine, methane rashes are concentrated in the transition zone shelf-

\footnotetext{
${ }^{1}$ National Space Facilities Control and Test Center, Ukraine
} 
continental slope in the north-western and north-western parts of the Black Sea $[1 ; 2 ; 3]$.

The frequency of activation of emissions and the large number of methane rashes localized in the paleo-delta of the Dnieper (Figure 1) attract the attention of many researchers $[1 ; 2 ; 3]$.

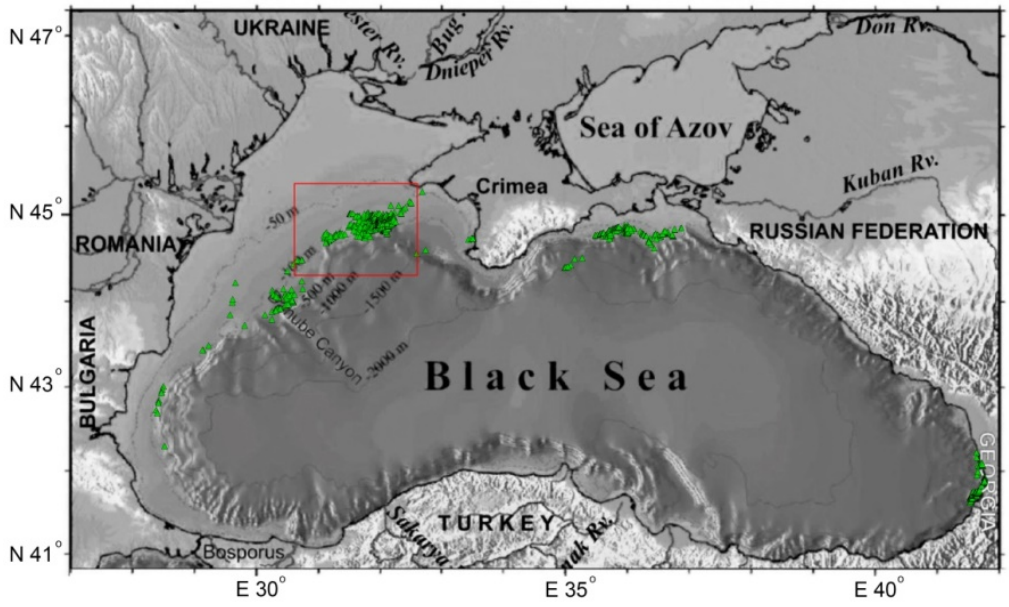

Figure 1. Test site on a fragment of the map of the Black Sea [4] with a diagram of the outflow of methane pages. Symbols: green triangles are methane leaks mapped according to research by Egorov et al., 2011; red rectangle - test site

Based on the data of geological, geochemical and geophysical studies $[3 ; 5 ; 6]$ it is known that in this area (Figure 1,2 ) is periodically activated more than 2000 thousand methane rashes, which emit a certain amount of gas rising from the bottom to the surface sea. The visualization of the number is shown on a three-dimensional graph (Figure 3), built in the Origin program in test access. The coordinates of methane rashes are taken from the catalog [5].

Methane outputs carry water masses with a reduced bottom mass temperature of $\sim 3-5^{\circ} \mathrm{C}$, and near the sea surface about $25^{\circ} \mathrm{C}$ (in summer) [7] and rising into the lower atmosphere, intensively absorbs thermal radiation from the Earth in the infrared region of the spectrum at wavelength 7,66 $\mu \mathrm{m}$ $[1 ; 7 ; 8]$. This phenomenon can be observed in different spectral (thermal and infrared) ranges in NASA satellite images (MODIS, NOAA, etc.), which allows to expand the possibilities of studying methane emissions in the marine environment. However, a set of additional data should be considered to 
determine the survey period, which should coincide with the period of activation of methane rashes.

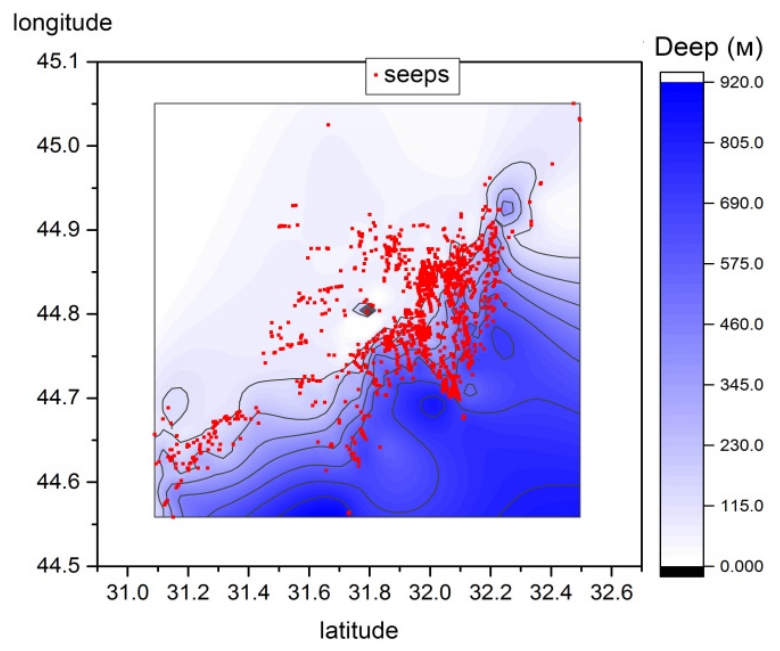

\section{Figure 2. Three-dimensional graph of methane rash localization in the Dnieper paleo-delta}

At this stage, it is impossible to accurately determine the amount of methane gas coming to the surface from the seabed using remote sensing. This is due to various factors: rapid methane dissipation, atmospheric phenomena, seasonality, changes in sea currents, and so on. It is known that the volume of gas increases [7;9] during increased seismic and tectonic activity in the region - this should be taken into account when choosing the date of the images.

Research methodology. At the first stage of the study, we analyze the seismotectonic activity of the region, which manifested itself in the form of strong earthquakes in Turkey in 1999 with magnitudes of 7.6 and 7.2 on the Richter scale near Izmit and Düzce. The tectonics of this region is formed by the movement of Eurasian, Arabian and African plates, which interact with each other and (Figure 3) [10] activate seismotectonic processes that affect tectonic activity in the region as a whole and are manifested in methane gas emissions in the Black Sea. 


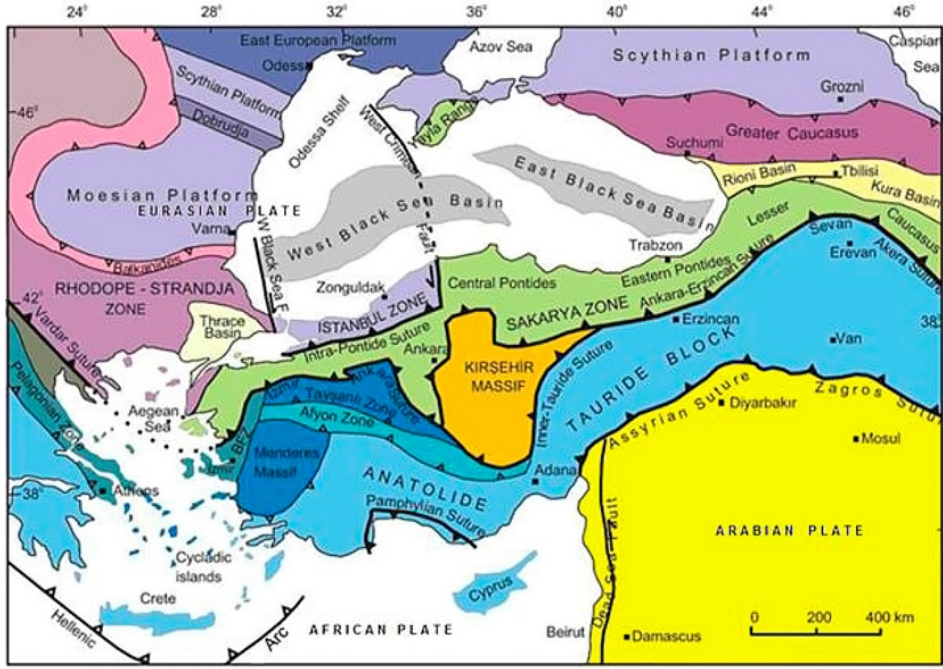

Figure 3. Tectonic map of Turkey and the surrounding area, according to [10]. Explanation: faults - dense lines, subduction zones filled triangles, active subduction zones - thick lines with open triangles, oceanic crust - gray colors. BFZ - Bornov zone Flush

In general, the study area of the paleo-delta of the Dnieper is influenced by tectonic processes occurring in the Black Sea region: Romania (Vrancea zone), Moldova, Turkey (mobile Anatolian plate).

Next, we monitor images from the MODIS satellite (Aqua / Terra) for several months before and after the earthquakes. We select the images that interest us: with the manifestations of anomalous clouds that appear over the areas of distribution of methane rashes during this period and carry out processing in specialized programs (SNAP, Q-Gis, etc.) in different spectral ranges.

For example, in 2016 there was increased seismic activity in the Black Sea region, which manifested itself in the form of earthquakes in Turkey, Romania on September 24, 2000 with a magnitude of 5.6 and an epicenter $153 \mathrm{~km}$ north of Bucharest. Which allows you to select the shooting data in these periods of 2000 or 2016.

After analyzing the selected images of the MODIS satellite (product MOD021KM) over the study area on a background of continuous clouds, which has a sharp decrease in temperature compared to the environment, an anomaly was detected (Figure 2), which was recorded among the clouds. This is the volume of methane gas, which is much warmer compared to the 
temperature of the clouds, sprays clouds forming a cloudless area that can be recorded on the short circuit $[1 ; 8]$.

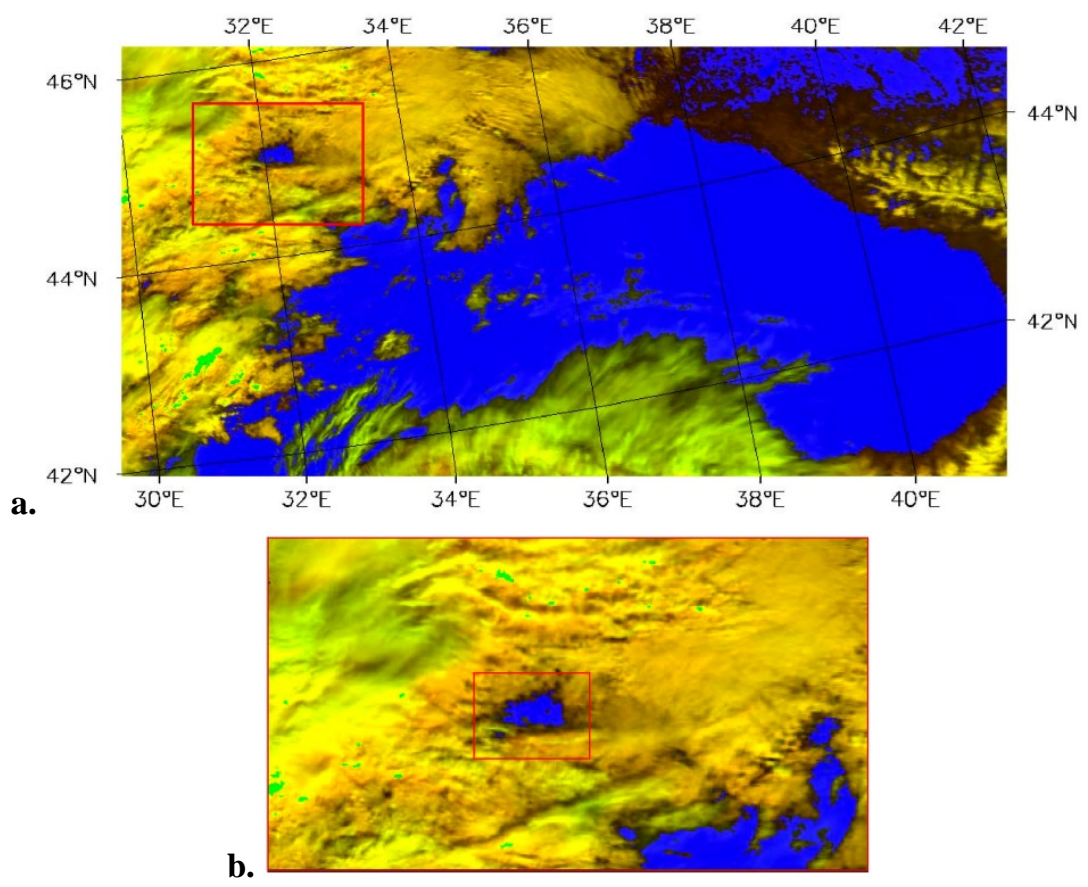

\begin{tabular}{|l|c|}
\hline \multicolumn{2}{|c|}{ Spectral ranges } \\
\hline R: & visible $0.890-0.920 \mu \mathrm{m}$, \\
\hline G: & near infrared $0.931-0.941 \mu \mathrm{m}$, \\
\hline B: & near infrared $0.862-0.877 \mu \mathrm{m}$. \\
\hline
\end{tabular}

Figure 3. a, b. Fragment of the scene MODIS (product MOD021KM) with an isolated area of the anomaly in the study area; date and time of the survey -3.03 .2000 and 9:20, the area without clouds is clearly observed against the background of cloud cover, this area is treated as an anomaly located above the study area and methane leakage. Explanation: red squares - a. research area, b. area with an anomaly

Of great importance is the temperature difference, methane rising from the seabed to the surface and further into the troposphere, much colder than surface water and warmer than the atmosphere, it provokes the formation of 
condensate in the form of small clouds over the methane outlets. This phenomenon is recorded in cloudless weather on space images of satellites in spectral ranges with a thematic direction: atmospheric phenomena, characteristics of clouds, water vapor and others. The Aqua / Terra satellite with the MODIS spectroradiometer is most suitable for such tasks.

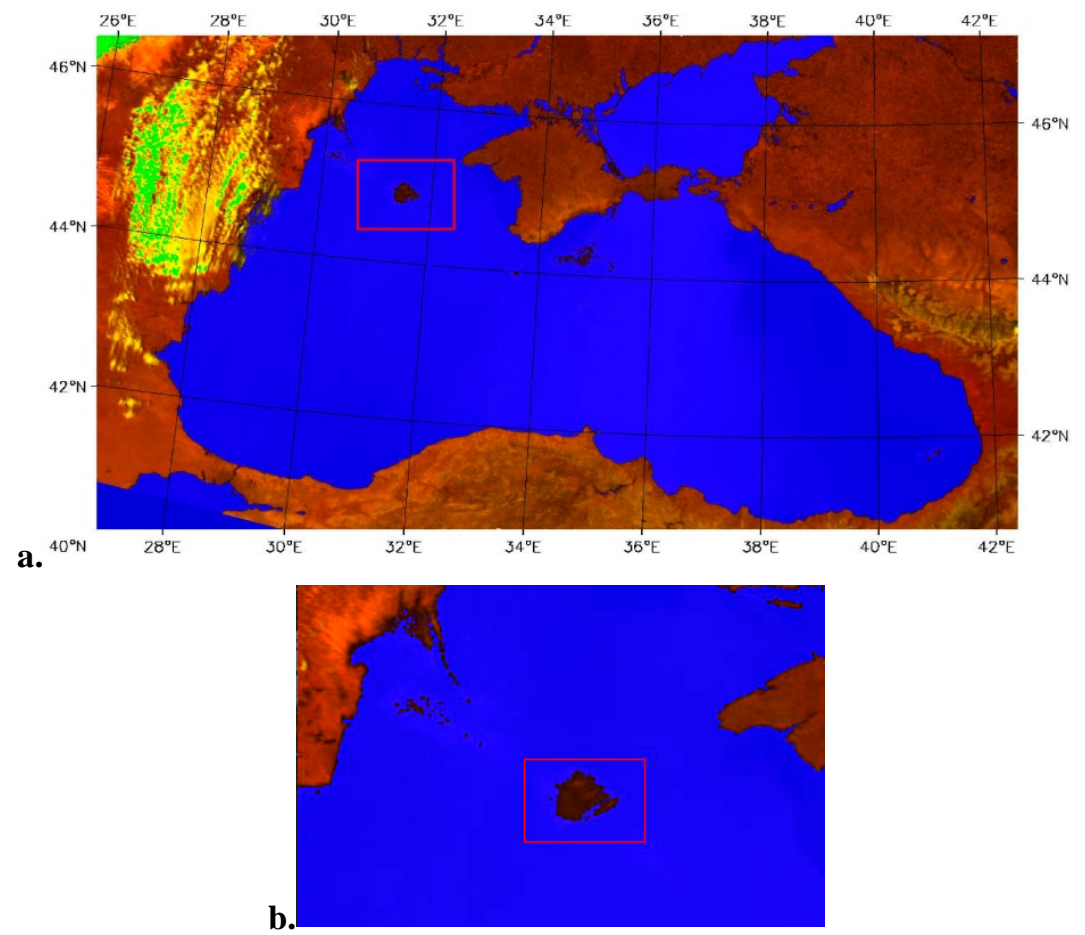

\begin{tabular}{|l|c|}
\hline \multicolumn{2}{|c|}{ Spectral ranges } \\
\hline R: & visible $0.890-0.920 \mu \mathrm{m}$, \\
\hline G: & near infrared $0.931-0.941 \mu \mathrm{m}$, \\
\hline B: & near infrared $0.862-0.877 \mu \mathrm{m}$. \\
\hline
\end{tabular}

Figure 4. a, b. A fragment of the scene MODIS (product MOD021KM) with an anomaly zone in the study area; date and time of the survey - 13.07.2000 and 8:55, the cloud cover is clearly visible and is interpreted as areas with abnormal clouds associated with methane impregnation activity. Explanation: red squares - a. study area, $b$. area with an anomaly 
Conclusions. The methods of remote sensing of the Earth and data from the Aqua / Terra satellites of the MODIS spectroradiometer can be used to solve geological problems and search for minerals by secondary characteristics. The frequency of the flight, which is two days, depending on the latitude, which allows you to monitor the dynamics of geological processes and conduct detailed monitoring. A necessary condition for this technique is to take into account tectonic, geophysical, lithological data and information on atmospheric and hydrological phenomena.

This method can record periods of activation of methane gas emissions on the sea surface from the bottom, due to the difference in temperature of the masses, which is closely related to the activation of seismic activity of the region.

\section{References:}

1. Melnichenko, T.A. (2018) Estimation of activity the methane seepage from the Black Sea floor using MODIS images and geosciences data. Bulletin of the University of Dnipro. Geology, geography, vol. 26, no. 20.

2. Lieven Naudts, Jens Greinertb, Yuriy Artemovc, Peter Staelens, Jeffrey Poorta, Pieter Van Rensbergen, Mare De B atist. (2006). Geological and morphological setting of 2778 methane seeps in the Dnepr paleo-delta, northwestern Black Sea Marine Geology, vol. 227, pp. 177-199.

3. Lejn A.Ju., Ivanov M.V. (2005). Krupnejshij na Zemle metanovyj vodoem [The largest methane reservoir in the world]. Priroda, vol. 2, pp. 18-26.

4. Irina Popescu, Nicolae Panin, Dan Jipa, Gilles Lericolais, Gabriel Ion (2015). Submarine canyons of the Black Sea basin with a focus on the Danube Canyon. Submarine canyon dynamics. (Italy, Sorrento, April 15-18, 2015), pp. 103-121.

5. Egorov V.N., Artemov Y.G., Gulin S.B. (2011). Metanovye sipy v Chernom more: sredoobrazujushhaja i jekologicheskaja rol' [Methane seeps in the Black Sea: Environmentforming and ecological role]. Sevastopol: ECOSEA Hydrophysics. (in Russian)

6. Shnyukov E.F., Stupina L.V., Rybak Ye.N. at all (2015). Gryazevye vulkani Chernogo morya (katalog). [Mud volcanoes of the Black Sea (catalog)]. Logos, p. 259. (in Russian)

7. Melnichenko T.A., Vorobiev A.I., Geykman A.M. (2016). Vplyv gheotektonichnoji aktyvnosti na obsjaghy ghazovykh vydilenj u pivnichnij chastyni Chornogho morja [Influence of the geotectonic activity on volumes of gas seeps in the north part of the Black Sea]. Dopovidi NAN Ukrajiny, vol. 3, pp. 55-60.

8. Melnichenko T. A. (2018). Remote research of geotectonic processes using the satellites MODIS (Aqua/Terra) images in the GIS program (for example, the Black Sea). XVII International Conference "Geoinformatics: Theoretical and Applied Aspects». (Ukraine, Kiev, May 14-17, 2018), Kiev: Geoinformatics, 2018, pp. 1-6.

9. Fleischer P., Orsi T.H., Richardson M.D., Anderson A.L. (2001). Distribution of free gas in marine sediments: a global overview. Geo-Marine Letters vol. 21, pp. 103-122.

10. Şakir Şahin C., Ertan Toker, Mohamed Farouk Abdelwahed (2017) The Determination of the Continental Borders in Anatolia Region fromthe LongWavelength Gravitational Data and Seismic Velocity Perturbation. European International Journal of Science and Technology, vol. 6, no. 9, December, pp. 1-17. 